in vivo $34: 703-708(2020)$

doi:10.21873/invivo.11827

\title{
Differences in Risk Factors for Melanoma in Young and Middle-aged Higher-risk Patients
}

\author{
JOHANNA S. PALVE ${ }^{1}$, NIINA J. KORHONEN ${ }^{2}$, TIINA H. LUUKKAALA ${ }^{3}$ and MINNA T. KÄÄRIÄINEN ${ }^{1}$ \\ ${ }^{1}$ Department of Plastic Surgery, Faculty of Medicine and Health Technology \\ and Tampere University Hospital, Tampere University, Tampere, Finland; \\ ${ }^{2}$ Department of Dermatology and Allergology, Tampere University Hospital and Faculty of Medicine \\ and Health Technology, Tampere University, Tampere, Finland; \\ ${ }^{3}$ Research, Development and Innovation Center, Tampere University Hospital and Health Sciences, \\ Faculty of Social Sciences, Tampere University, Tampere, Finland
}

\begin{abstract}
Background/Aim: Differences in risk factors for melanoma between young adults (18-39 years) and middleaged (40-60 years) are not well documented. In this study, we aimed to determine differences in risk factors and characteristics of melanoma between these groups. Patients and Methods: This retrospective study is a review on 330 patients, including 250 middle-aged and 80 young adults, during the period 2006-2016 in the Tampere university hospital, in Finland. Results: Forty-one per cent of middleaged and $47 \%$ of young adults were defined as higher-risk patients. High nevus count was the most common host risk factor in both groups. Young were more likely to have a family history of melanoma. Middle-aged had more often excessive intermittent sun exposure and a history of sunburn. Host risk characteristics were less commonly associated with thicker melanomas. Conclusion: A high number of patients have host risk factors for melanoma. Several differences exist in risk factors and characteristics of melanomas between young adults and middle-aged patients.
\end{abstract}

Several host characteristics have been associated with the risk of melanoma. These include the phenotype, the number of nevi, a family history of melanoma (1-3), and the presence of dysplastic nevi $(4,5)$. Other risk factors include sun exposure and severe sunburns (6). The association of sun exposure with melanoma risk is influenced by host characteristics. In fact, exposure patterns might be of less

This article is freely accessible online.

Correspondence to: Johanna Palve, Department of Plastic Surgery, Tampere University Hospital, Teiskontie 35, 33521 Tampere, Finland. Tel: +358 3 31167506, e-mail: johanna.palve@pshp.fi

Key Words: Melanoma, young adult, middle-aged, risk factors. importance compared to the individual response to sun exposure $(6,7)$. Differences in melanomas by anatomic site, histology, sex and age, suggest that both host characteristics and behavioral factors influence risk (8). Country-specific variations are related to interactions between sun exposure and skin type, postulated divergent pathways (intermittent $v s$. cumulative exposure) and critical periods of exposure (6). Sunburn is a stronger predictor compared to intermittent exposure itself (7). Especially sun exposure and sunburn occurrence during childhood are key risk factors for melanoma later in life (9).

There is a large diversity of melanoma across the age spectrum. Melanomas in patients at the extremes of age have a distinct natural history, but there are also differences in characteristics of melanomas within age groups between these extremes (10). In this study, we compared risk factors and characteristics of melanoma in young and middle-aged adults and tried to identify possible differences between these groups. Understanding the risk of melanoma in different age groups and taking into account the countryspecific variations is important for the development of effective cancer control activities.

\section{Patients and Methods}

New invasive cutaneous melanomas were picked up from the melanoma database at Tampere university hospital (Finland) from

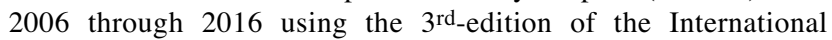
Classification of Diseases for Oncology (ICD-O-3) code C43. Patients from 18 to 60 years of age were included in the study. In Finland, $30 \%$ of inhabitants have Fitzpatrick's skin phototypes I or II and $60 \%$ have type III (11). All patients in this study had skin types I to III. We ensured that there were no patients duplicated in the study (i.e. with two primary melanomas during the 10 -year period of the study).

Permission to access the clinical records was obtained from the scientific center of Tampere University Hospital. The clinical records of all patients were reviewed. 
Patients were divided to two age groups: i) younger than 40 years ( $<40$ years) and ii) 40-60 years of age. The location of the tumor was scored: i) trunk, ii) upper limb, iii) lower limb and iv) head and neck. The Breslow thickness (12) reported by a dermatopathologist was recorded. The histological subtypes were classified: i) superficial spreading melanoma (SSM), ii) nodular melanoma (NM), iii) lentigo maligna melanoma (LMM), and iv) acral melanoma (AM). The number of other, biopsy-proven, primary melanomas (OM) and dysplastic nevi (DN) was recorded. The nevus count, assessed by a doctor during the patient's first visit in the skin cancer unit, was also recorded. High nevus count (HNC) was defined as having $\geq 50$ nevi.

Information about: i) a history of severe sunburns during childhood (at least two painful sunburns that lasted more than one day), ii) a history of excessive intermittent sun exposure, iii) a family history of melanoma in a first-degree relative (FH), was collected by a doctor after interviewing patients during their first visit to our skin cancer unit.

Statistical analysis. Categorical variables were described by the number of patients with percentages. Differences between categorical variables were tested by Pearson chi-square test, or Fisher's exact test if Pearson chi-square test assumptions were not valid. Distributions of the skewed continuous variables were tested using the Mann-Whitney test. For multiple comparisons, the Bonferroni correction was performed and $p$-values under 0.0125 were considered statistically significant, otherwise we used the margin of $p$-Values under 0.05 as significant. The analyses were carried out using the IBM SPSS Statistics for Windows software, version 23.0 (IBM Corp., Armonk, NY, USA).

\section{Results}

A total of 1,248 cases of new invasive cutaneous melanomas were detected in 667 men and 581 women between 1.1.2006 and 31.12.2016. Among these patients, a total of 330 (men: $\mathrm{n}=150$; women: $\mathrm{n}=180$ ) patients were 60 years of age or younger and were included in the study. Of these patients, 250 were middle-aged (40-60 years) and 80 were young (1839 years) adults.

Host characteristics, behavioral risk factors and melanoma characteristics for patients $<40$ years vs. 40-60 years. HNC $(26 \%, 21 / 80)$ was the most common host risk factor in the young adults' group, followed by having DN (20\%, 16/80), FH $(19 \%, 15 / 80)$ and OM $(10 \%, 8 / 80)$ (Table I). In middle-aged group, HNC $(28 \%, 69 / 250)$, was also the most common risk factor, followed by DN $(24 \%, 57 / 250)$, OM $(13 \%, 32 / 250)$ and FH $(9 \%, 22 / 250)$. The young patients were, on average, less likely to have excessive intermittent sun exposure $(30 \% \mathrm{vs}$. $44 \%, p=0.031)$ and a history of sunburn in childhood compared to the middle-aged group ( $25 \%$ vs. $43 \%, p=0.004)$.

The young group had a higher proportion of SSM $(86 \%$ vs. $77 \%, p=0.178)$, fewer other types of melanomas and thinner (Md Breslow $0.6 \mathrm{~mm}$ vs. $1.0 \mathrm{~mm}, p<0.001$ ) melanomas compare to middle-aged patients. Young were less likely to have a melanoma situated on the trunk (40\% vs. 50\%) and lower limb (21\% vs. 26\%) area and more likely to have a melanoma on the upper limb (24\% vs. 14\%) and head and neck (15\% vs. 10\%) area $(p=0.082)$. These differences were not statistically significant (Table I).

Differences in melanoma characteristics and behavioral risk factors in patients with vs. without high-risk host characteristics. Patients with $\mathrm{FH}$ were, on average, more likely to have thin $(\mathrm{Br}<1 \mathrm{~mm})$ melanomas $(73 \%$ vs. $50 \%$, $p=0.026$ ) compared to patients without FH (Table II). The same was also observed in patients with DN (65\% vs. $48 \%$, $p=0.021)$, HNC (56\% vs. $51 \%, p=0.711)$ and OM (55\% vs. $52 \%, p=0.670)$. SSM was most common for patients with FH $(92 \%)$ compared to those with HNC (83\%), OM $(80 \%)$ or DN $(75 \%)$. Patients with HNC were more likely to have melanoma on the trunk ( $57 \%$ vs. $45 \%, p=0.105)$ compare to patients without HNC. Otherwise, there were no notable differences in the body site distribution of melanomas among patients with host risk factors. Patients with DN were more likely $(57 \%)$ to have excessive intermittent sun exposure compared to patients with HNC (46\%), OM (40\%) or FH (35\%). Patients with FH were less likely to have a history of sunburn during childhood (38\%), compared to those with HNC (52\%), OM (53\%) and DN (48\%).

\section{Discussion}

Several findings emerged from this study of 330 young and middle-aged cutaneous melanoma patients. A higher number of patients ( $41 \%$ of middle-aged and $47 \%$ of young) were defined as higher risk owing to $\mathrm{FH}, \mathrm{OM}, \mathrm{HNC}$ or DN compared to an earlier study (3), in which $11 \%$ of $<40$ and $33 \%$ of $40-59$-year-old patients were defined as high-risk patients. This difference may, however, be explained by the different definition of risk factors between studies, as in our study DN was also counted in. The problem in comparing findings from the literature, is that, according to our knowledge, there are only a few studies which compare risk factors for melanoma in young and middle-aged adults.

The ratio of patients with $\mathrm{FH}$ is in agreement with other studies, but findings differ with regards to age distribution $(8,13,14)$. In our study, young adults were more likely to have $\mathrm{FH}$ compared to middle-aged, while in other studies patients older than 40 years were more likely to have $\mathrm{FH}$. Whether this difference can be explained by country-specific variations in the population remains unclear. Different results have also been observed between studies concerning the Breslow thickness of melanomas in patients with FH. Li et al. (8), have found that individuals with FH might be more likely to develop thicker melanomas, while Chiarugi with cowriters (14) did not find differences in thickness between familiar and sporadic melanomas. We found that a majority of patients with $\mathrm{FH}$ had thin melanoma, which is in 
Table I. Descriptive statistics for risk factors and characteristics of melanoma according to age group in all melanomas included in the study $(n=330)$.

\begin{tabular}{|c|c|c|c|}
\hline & $<40$ years $(\mathrm{n}=80)$ & $40-60$ years $(n=250)$ & $p$-Value \\
\hline Gender, n (\%) & & & 0.008 \\
\hline Male & $26(33)$ & $124(50)$ & \\
\hline Female & $54(67)$ & $126(50)$ & \\
\hline High nevus count, $\mathrm{n}(\%)$ & & & 0.813 \\
\hline No & $59(74)$ & $181(72)$ & \\
\hline Yes & $21(26)$ & $69(28)$ & \\
\hline Family history of melanoma, n (\%) & & & 0.014 \\
\hline No & $65(81)$ & $228(91)$ & \\
\hline Yes & $15(19)$ & $22(9)$ & \\
\hline Other melanomas, n (\%) & & & 0.504 \\
\hline No & $72(90)$ & $218(87)$ & \\
\hline Yes & $8(10)$ & $32(13)$ & \\
\hline Dysplastic nevus, n (\%) & & & 0.504 \\
\hline No & $64(80)$ & $191(76)$ & \\
\hline Yes & $16(20)$ & $57(24)$ & \\
\hline High-risk patients, n (\%) & & & 0.291 \\
\hline No & $42(53)$ & $148(59)$ & \\
\hline Yes & $38(47)$ & $102(41)$ & \\
\hline Excessive sun exposure, $\mathrm{n}(\%)$ & & & 0.031 \\
\hline No & $56(70)$ & $141(56)$ & \\
\hline Yes & $24(30)$ & $109(44)$ & \\
\hline History of sunburn in childhood, $\mathrm{n}(\%)$ & & & 0.004 \\
\hline No & $60(75)$ & $142(57)$ & \\
\hline Yes & $20(25)$ & $108(43)$ & \\
\hline Breslow, Md (IQR) & $0.60(0.41-1.18)$ & $1.00(0.60-2.00)$ & $<0.001$ \\
\hline Breslow, n (\%) & & & 0.003 \\
\hline$<1$ & $54(68)$ & $118(47)$ & \\
\hline $1-2$ & $20(25)$ & $80(32)$ & \\
\hline$>2$ & $6(7)$ & $52(21)$ & \\
\hline Subtype, n (\%) & & & 0.178 \\
\hline SSM & $69(86)$ & $192(77)$ & \\
\hline LMM & $4(5)$ & $22(9)$ & \\
\hline NM & $7(9)$ & 27 (11) & \\
\hline $\mathrm{AM}$ & $0(0)$ & $9(3)$ & \\
\hline Location of melanoma & & & 0.082 \\
\hline Trunk & $32(40)$ & $126(50)$ & \\
\hline Upper limb & $19(24)$ & $35(14)$ & \\
\hline Lower limb & $17(21)$ & $64(26)$ & \\
\hline Head \& Neck & $12(15)$ & $25(10)$ & \\
\hline
\end{tabular}

High-risk patients: Hight nevus count, family history, other melanomas and/or dysplastic nevus; Years: age at the time of diagnosis; Md: median; IQR: interquartile range. Differences between age-groups were analyzed using Mann-Whiney test (continuous, but skewed factors), Pearson chisquare test or Fisher's exact test, if Pearson chi-square test assumptions were not valid (categorical factors).

agreement with the study by Aguilera and cowriters (13). This finding suggests that melanoma patients with FH may have an increased risk awareness and could benefit from an early detection of melanoma.

A high number of nevi is the most significant phenotypic risk factor for melanoma and is in part genetically determined (15). Having HNC was the most common host risk factor for melanoma in both young and middle-aged adults. In these patients, melanomas were more likely thin and located in the trunk area, confirming data from previous melanoma studies $(4,15)$. It has been suggested that individuals with $\mathrm{HNC}$ may be more likely to practice skin self-examination, which may lead to an earlier detection of melanoma (4). There is also a possibility that the genetic determinants of nevi number may be associated with biological differences in melanoma tumors (15). Most patients with melanoma, however, did not have HNC. The total nevus count should not be the only reason for performing a skin examination or determining a patient's risk-status. 
in vivo $34: 703-708(2020)$

Table II. Patient and melanoma characteristics and behavioral risk factors for patients according to high-risk host characteristics.

\begin{tabular}{|c|c|c|c|c|c|c|c|c|c|c|c|c|c|c|c|c|c|c|c|c|}
\hline & \multicolumn{2}{|c|}{$\begin{array}{c}\mathrm{FH} \\
(\mathrm{n}=37)\end{array}$} & \multicolumn{2}{|c|}{$\begin{array}{c}\text { No FH } \\
(n=293)\end{array}$} & \multirow[b]{2}{*}{$p$-Value } & \multicolumn{2}{|c|}{$\begin{array}{c}\mathrm{HNC} \\
(\mathrm{n}=90)\end{array}$} & \multicolumn{2}{|c|}{$\begin{array}{c}\text { No HNC } \\
(\mathrm{n}=240)\end{array}$} & \multirow[b]{2}{*}{$p$-Value } & \multicolumn{2}{|c|}{$\begin{array}{c}\mathrm{OM} \\
(\mathrm{n}=40)\end{array}$} & \multicolumn{2}{|c|}{$\begin{array}{l}\text { No OM } \\
(n=290)\end{array}$} & \multirow[b]{2}{*}{$p$-Value } & \multicolumn{2}{|c|}{$\begin{array}{c}\mathrm{DN} \\
(\mathrm{n}=75)\end{array}$} & \multicolumn{2}{|c|}{$\begin{array}{l}\text { No DN } \\
(\mathrm{n}=255)\end{array}$} & \multirow[b]{2}{*}{$p$-Valu } \\
\hline & $\mathrm{n}$ & $(\%)$ & $\mathrm{n}$ & $(\%)$ & & $\mathrm{n}$ & $(\%)$ & $\mathrm{n}$ & $(\%)$ & & $\mathrm{n}$ & $(\%)$ & $\mathrm{n}$ & $(\%)$ & & $\mathrm{n}$ & $(\%)$ & $\mathrm{n}$ & $(\%)$ & \\
\hline Age, yrs & & & & & 0.014 & & & & & 0.813 & & & & & 0.504 & & & & & 0.504 \\
\hline$<40$ & 15 & (40) & 65 & (22) & & 21 & (23) & 59 & (25) & & 8 & (20) & 72 & $(25)$ & & 16 & (21) & 64 & (25) & \\
\hline $40-60$ & 22 & $(60)$ & 228 & (78) & & 69 & (77) & 181 & (75) & & 32 & (80) & 218 & (75) & & 59 & (79) & 191 & (75) & \\
\hline Gender & & & & & 0.323 & & & & & 0.636 & & & & & 0.460 & & & & & 0.280 \\
\hline Male & 14 & (38) & 136 & (46) & & 39 & (43) & 111 & (46) & & 16 & (40) & 134 & (46) & & 30 & $(40)$ & 120 & (47) & \\
\hline Female & 23 & (62) & 157 & (54) & & 51 & (57) & 129 & (54) & & 24 & (60) & 156 & (54) & & 45 & $(60)$ & 135 & (53) & \\
\hline Subtype & & & & & 0.204 & & & & & 0.585 & & & & & 0.858 & & & & & 0.004 \\
\hline SSM & 34 & (92) & 227 & (78) & & 75 & (83) & 186 & (78) & & 32 & (80) & 229 & (79) & & 56 & (75) & 205 & (80) & \\
\hline NM & 1 & (3) & 25 & $(8)$ & & 6 & (7) & 20 & (8) & & 4 & (10) & 22 & $(8)$ & & 13 & (17) & 13 & (5) & \\
\hline LMM & 1 & (3) & 33 & (11) & & 8 & (9) & 26 & (11) & & 3 & (8) & 31 & (11) & & 5 & (7) & 29 & (11) & \\
\hline $\mathrm{AM}$ & 1 & (3) & 8 & (3) & & 1 & (1) & 8 & (3) & & 1 & (2) & 8 & (3) & & 1 & (1) & 8 & (3) & \\
\hline Location & & & & & 0.255 & & & & & 0.105 & & & & & 0.959 & & & & & 0.702 \\
\hline $\operatorname{Tr}$ & 19 & (51) & 139 & (47) & & 51 & (57) & 107 & (45) & & 19 & (48) & 139 & (48) & & 35 & (47) & 123 & (48) & \\
\hline UL & 5 & (14) & 49 & (17) & & 15 & (17) & 39 & (16) & & 7 & (17) & 47 & (16) & & 14 & (19) & 40 & (16) & \\
\hline $\mathrm{LL}$ & 12 & (32) & 69 & (24) & & 19 & (21) & 62 & (26) & & 9 & (23) & 72 & (25) & & 20 & (27) & 61 & (24) & \\
\hline $\mathrm{H} \& \mathrm{~N}$ & 1 & (3) & 36 & (12) & & 5 & (6) & 32 & (13) & & 5 & (12) & 32 & (11) & & 6 & (8) & 31 & (12) & \\
\hline $\mathrm{Br}, \mathrm{mm}$ & & & & & 0.026 & & & & & 0.455 & & & & & 0.884 & & & & & 0.021 \\
\hline$<1.00$ & 27 & (73) & 145 & (50) & & 50 & (56) & 122 & (51) & & 22 & (55) & 150 & (52) & & 49 & (65) & 123 & (48) & \\
\hline $1.00-2.00$ & 6 & (16) & 94 & (32) & & 28 & (31) & 72 & (30) & & 12 & (30) & 88 & (30) & & 14 & (19) & 86 & (34) & \\
\hline$>2.00$ & 4 & (11) & 54 & (18) & & 12 & (13) & 46 & (19) & & 6 & (15) & 52 & (18) & & 12 & (16) & 46 & (18) & \\
\hline Sun & & & & & 0.496 & & & & & 0.234 & & & & & 0.967 & & & & & 0.001 \\
\hline Yes & 13 & (35) & 120 & (41) & & 41 & (46) & 92 & (38) & & 16 & (40) & 117 & (40) & & 43 & (57) & 90 & (35) & \\
\hline No & 24 & (65) & 173 & (59) & & 49 & (54) & 148 & (62) & & 24 & $(60)$ & 173 & $(60)$ & & 32 & (43) & 165 & (65) & \\
\hline Sunburn & & & & & 0.900 & & & & & 0.002 & & & & & 0.058 & & & & & 0.063 \\
\hline Yes & 14 & (38) & 114 & (39) & & 47 & (52) & 81 & (34) & & 21 & (53) & 107 & (37) & & 36 & (48) & 92 & (36) & \\
\hline No & 23 & (62) & 179 & (61) & & 43 & (48) & 159 & (66) & & 19 & (47) & 183 & (63) & & 39 & (52) & 163 & (64) & \\
\hline
\end{tabular}

SSM: Superficial spreading melanoma; NM: nodular melanoma; LMM: lentigo maligna melanoma; AM: acral melanoma; Tr: Trunk; UL: upper limb; LL: lower limb; H\&N: head and neck; FH: family history of melanoma in first-degree relative; HNC: high nevus count; OM: other primary melanomas; DN: dysplastic nevi; Br: Breslow thickness; Sun: excessive intermittent sun exposure; Sunburn: history of sunburn in childhood. Differences between FH and no FH, HNC and no HNC, OM and no OM, and DN and no DN were analyzed using Pearson chi-square test, or Fisher's exact test, if Pearson chi-square test assumptions were not valid. Due to the multiple comparisons, Bonferroni correction were used, and $p$-values under 0.0125 were considered as statistically significant.

Melanomas in patients with DN were more likely to be thinner and presented more commonly in middle-aged patients; observations adding support to prior studies $(4,5)$. The subtype of melanomas, however, differed between studies. In our study, melanomas in patients with DN were less likely to be SSM and more likely NM compared to patients without DN or other host risk factors. In other studies, SSM was a more common subtype and NM less frequent one in patients with $\mathrm{DN}$ compared to patients without DN $(4,5)$. SSM is considered to be less aggressive and is more often detected as a thinner tumor with a slower growth compared to NM (16).

The proportion of patients with biopsy-proven OM was higher here $(11 \%)$ compared to previous studies with regards to all age groups $(1.2-8.2 \%)(17-19)$. The reason for this difference between studies is not clear, however, one reason may be the different age groups studied. In our study, only patients 60 years or younger were included. In prior studies, OM were diagnosed in patients with different predominance on gender and age. Observations supporting both males of an older age (17) and females of an early age (19) have been published. In our study, OM were more likely diagnosed in the middle-aged group with female predominance. Even one tenth of $\leq 60$-year-old melanoma patients developed a second primary melanoma. Careful education of melanoma patients could facilitate an earlier diagnosis of a subsequent second primary melanoma.

When comparing behavioral risk factors, we observed that young adults had less excessive sun exposure during adulthood and a history of sunburn during childhood compared to middle-aged patients. It has been suggested in earlier studies that public health campaigns promote 
awareness of the risk of sun exposure in Australia and Europe and may have contributed to stabilizing or declining the melanoma incidence rates in young adults (1). Whether this is true also in our population remains to be studied. In this study, over one third of the patients with high-risk host characteristics had a history of excessive intermittent sun exposure or a history of sunburns during childhood. Similar results have been previously reported by Chiarugi et al. (14) in patients with FH. This finding suggests that patients with host risk characteristics are not careful enough to prevent melanoma. Continued close monitoring and information about sun protection of high-risk population is necessary.

We acknowledge several limitations in our study. First, certain subgroups are limited by the small numbers of patients. The disproportion between the two age groups of the study, can be explained by the different distribution of melanoma depending on age but can still limit the interpretation of the results. Second, this study is limited to studying patients at an academic center rather than from a cohort of a wider population. Despite this limitation, our patients were referred from surrounding regions as well. Third, the familial status was based on patients' self-reported family history. To minimize the risk of recall we applied the criteria with no more distance than the first-degree relatives. Fourth, skin cancer patients may overreport or underreport their sunburn or sun exposure experience, producing biased estimates of the true association. On the other hand, the majority of studies use verbal reports or self-reports to measure habitual sun exposure. Despite well-known limitations of verbal reports, these measures were suggested to be the most practical for both population surveillance and intervention research (20).

We think that these results lead to some scientific and health educational suggestions. Our findings support prior studies, while also offering distinct new information about melanomas in a different country-specific population. The findings from this study may help identify strategies to further stratify patients for more targeted patient education and potential screening.

In conclusion, young and middle-aged adults have differences in risk factors for melanoma. Our data support more intensive skin cancer screening for patients of 60 years of age or younger with DN. The characteristics of melanomas in higher-risk patients in our study population have some differences compared to the characteristics described in earlier studies, supporting the existence of country-specific variations in melanomas. Characterization of these features may assist in understanding of heterogeneity of melanoma and targeting country-specific cancer treatment and control activities.

\section{Conflicts of Interest}

The Authors declare that they have no conflicts of interest.

\section{Authors' Contributions}

Writing and acquisition of data: Palve $\mathrm{J}$; Analysis and interpretation of data: Palve $J$ and Luukkaala T; Review and revision of the manuscript: Korhonen $\mathrm{N}$ and Kääriäinen $\mathrm{M}$.

\section{References}

1 Weir HK, Marrett LD, Cokkinides V, Barnholtz-Sloan J, Patel P, Tai E, Jemal A, Li J, Kim J and Ekwueme DU: Melanoma in adolescents and young adults (ages 15-39 years): United States, 1999-2006. J Am Acad Dermatol 65(5): S38-49, 2011. PMID: 22018066. DOI: 10.1016/j.jaad.2011.04.038

2 Slape D, Tang J, Lawless R, McCrossin I and Frew JW: A retrospective cohort study of melanoma prevalence stratified by body site in a regional Australian population 1994-2017: Sitespecific protective mechanisms. Photodermatol Photoimmunol Photomed 35(3): 135-140, 2019. PMID: 30381854. DOI: $10.1111 /$ phpp. 12436

3 Watts CG, Madronio C, Morton RL, Goumas C, Armstrong BK, Curtin A, Menzies SW, Mann GJ, Thompson JF and Cust AE: Clinical features associated with individuals at higher risk of melanoma. A population based study. JAMA Dermatol 153(1): 2329, 2017. PMID: 27829101. DOI: 10.1001/jamadermatol.2016.3327

4 Geller AC, Mayer JE, Sober AJ, Miller DR, Argenziano G, Johnson TM and Swetter SM: Total nevi, atypical nevi, and melanoma thickness. An analysis of 566 patients at 2 US centers. JAMA Dermatol 152(4): 413-418, 2016. PMID: 26934430. DOI: 10.1001/jamadermatol.2016.0027

5 Tan SY, Strazzulla LC, Li X, Park JJ, Lee SJ and Kim CC: Association of clinicopathological features of melanoma with total naevus count and a history of dysplastic naevi: a crosssectional retrospective study within an academic centre. Clin Exp Dermatol 43(5): 566-572, 2018. PMID: 29450912. DOI: $10.1111 /$ ced.13393

6 Erdmann F, Lortet-Tieulent J, Schüz J, Zeeb H, Greinert R, Breitbart EW and Bray F: International trends in the incidence of malignant melanoma 1953-2008 - are recent generations at higher or lower risk? Int J Cancer 132: 385-400, 2013. PMID: 22532371. DOI: $10.1002 / \mathrm{ijc} .27616$

7 Cust AE, Mishra K and Berwick M: Melanoma-role of the environment and genetics. Photochem Photobiol Sci 17(12): 1853-1860, 2018. PMID: 30113042. DOI: 10.1039/c7pp00411g

8 Li WQ, Cho E, Wu S, Li S, Matthews NH and Qureshi AA: Host characteristics and risk of incident melanoma by Breslow thickness. Cancer Epidemiol Biomarkers Prev 28(1): 217-224, 2019. PMID: 30341099. DOI: 10.1158/1055-9965.EPI-18-0607

9 Wu YP, Parsons BG, Aspinwall LG, Hay JL, Boucher KM, Caputo HC, Mooney R, Grossman D and Leachman SA: Parent and child perspective barriers to child sun protection and their association with sun protection strategies among children of melanoma survivors. Pediatr Dermatol 36(3): 317-323, 2019. PMID: 30895676. DOI: 10.1111/pde.13796

10 Balch CM, Soong S-j, Gershenwald JE, Thompson JF, Coit DG, Atkins MB, Ding S, Cochran AJ, Eggermont AM, Flaherty KT, Gimotty PA, Johnson T, Kirkwood JM, Leong SP, McMasters KM, Mihm MC, Morton DL, Ross MI and Sondak V: Age as prognostic factor in patients with localized melanoma and regional metastases. Ann Surg Oncol 20(12): 3961-3968, 2013. PMID: 23838920. DOI: 10.1245/s10434-013-3100-9 
11 Jansén CT: Self-reported skin type and reactivity to UVB, UVA and PUVA irradiation. Photodermatol 6(5): 234-236, 1989. PMID: 2616365.

12 Breslow A: Thickness, cross-sectional areas and depth of invasion in the prognosis of cutaneous melanoma. Ann Surg 172(5): 902-908, 1970. PMID: 5477666. DOI: 10.1097/0000 0658-197011000-00017

13 Aguilera P, Malvehy J, Carrera C, Palou J, Puig-Butillé JA, Alòs L, Badenas $\mathrm{C}$ and Puig S: Clinical and histopathological characteristics between familial and sporadic melanoma in Barcelona, Spain. J Clin Exp Dermatol Res 5(5): 231-240, 2014. PMID: 25893138. DOI:10.4172/2155-9554.1000231

14 Chiarugi A, Nardini P, Crocetti E, Carli P, De Giorgi V, Borgognoni L, Brandani P, Pimpinelli N, Manganoni AM, Quaglino $\mathrm{P}$ and GIPMe Participants Centres: Familial and sporadic melanoma: different clinical and histopathological features in the Italian population - a multicenter epidemiological study- by GIPMe (Italian multidisciplinary group on melanoma). JEADV 26(2): 194-199, 2012. PMID: 21429041. DOI: 10.1111/ j.1468-3083.2011.04035.x

15 Ribero S, Davies JR, Requena C, Carrera C, Glass D, Rull R, Vidal-Sicart S, Vilalta A, Alos L, Soriano V, Quaglino P, Traves V, Newton-Bishop JA, Nagore E, Malvehy J, Puig S and Bataille V: High nevus counts confer a favorable prognosis in melanoma patients. Int J Cancer 137(7): 1691-1698, 2015. PMID: 25809795. DOI: $10.1002 / \mathrm{ijc} .29525$

16 Warycha MA, Christos PJ, Mazumdar M, Darvishian F, Shapiro RL, Berman RS, Pavlick AC, Kopf AW, Polsky D and Osman I: Changes in the presentation of nodular and superficial spreading melanomas over 35 years. Cancer 113(12): 3341-3348, 2008. PMID: 18988292. DOI: $10.1002 /$ cncr.23955
17 Menzies S, Barry R and Ormond P: Multiple primary melanoma: a single centre retrospective review. Melanoma Research 27(6): 638-640, 2017. PMID: 29076952 DOI: 10.1097/CMR.000000 0000000395

18 DiFronzo LA, Wanek LA and Morton DL: Earlier diagnosis of second primary melanoma confirms the benefits of patient education and routine postoperative follow-up. Cancer 91(8): 1520-1524, 2001. PMID: 11301400. DOI: 10.1002/10970142(20010415)91:8\%3C1520::aid-cncr1160\%3E3.0.co;2-6

19 Stam-Posthuma JJ, van Duinen C, Scheffer E, Vink J and Bergman W: Multiple primary melanomas. J Am Acad Dermatol 44(1): 22-27, 2001. PMID: 11148472. DOI: 10.1067/mjd.2001. 110878

20 Glanz K, Yaroch AL, Dancel M, Saraiya M, Crane LA, Buller DB, Manne S, O'Riordan DL, Heckman CJ, Hay J and Robinson JK: Measures of sun exposure and sun protection practices for behavioral and epidemiologic research. Arch Dermatol 144(2): 217-222, 2008. PMID: 18283179. DOI: 10.1001/archdermatol. 2007.46
Received December 10, 2019

Revised January 18, 2020

Accepted January 20, 2020 